\title{
Erratum: RTN1 mediates progression of kidney disease by inducing ER stress
}

Ying Fan, Wenzhen Xiao, Zhengzhe Li, Xuezhu Li, Peter Y. Chuang, Belinda Jim, Weijia Zhang, Chengguo Wei, Niansong Wang, Weiping Jia, Huabao Xiong, Kyung Lee \& John C. He

Nature Communications 6:7841 doi: 10.1038/ncomms8841 (2015); Published 31 Jul 2015; Updated 22 Oct 2015

The original version of the Supplementary Information attached to this Article did not contain Supplementary Tables 1-7. The HTML has now been updated to include a corrected version of the Supplementary Information. article's Creative Commons license, unless indicated otherwise in the credit line; if the material is not included under the Creative Commons license, users will need to obtain permission from the license holder to reproduce the material. To view a copy of this license, visit http://creativecommons.org/licenses/by/4.0/
} 